\title{
Perspective
}

PERSPECTIVE Actualité en histoire de l'art

2| 2013

Brasil

\section{Modernismo brasileiro: entre a consagração e a contestação}

Ana Paula Cavalcanti Simioni

\section{(2) OpenEdition}

1 Journals

\section{Edição electrónica}

URL: http://journals.openedition.org/perspective/5539

DOI: 10.4000/perspective.5539

ISSN: 2269-7721

Editora

Institut national d'histoire de l'art

Refêrencia eletrónica

Ana Paula Cavalcanti Simioni, « Modernismo brasileiro: entre a consagração e a contestação ", Perspective [Online], 2 | 2013, posto online no dia 19 fevereiro 2016, consultado o 10 dezembro 2020. URL : http://journals.openedition.org/perspective/5539; DOI : https://doi.org/10.4000/perspective. 5539

Este documento foi criado de forma automática no dia 10 dezembro 2020. 


\title{
Modernismo brasileiro: entre a consagração e a contestação
}

\author{
Ana Paula Cavalcanti Simioni
}

\section{NOTA DO EDITOR}

Cet article existe en traduction française : Le modernisme brésilien, entre consécration et contestation

1 Em 1995, o colecionador argentino Eduardo Constantini adquiriu na Christie's de Nova York a tela Abaporu, de Tarsila do Amaral, finalizada em 1928. A transação foi emblemática por tratar-se de o maior valor já atingido por uma pintura brasileira no mercado internacional (1,3 milhões de dólares), bem como por toda a comoção que sua venda causou no país. O fato de hoje estar exposta no importante Museo de Arte Latinoamericano de Buenos Aires (MALBA), ombreada a nomes consagrados como os de Frida Kahlo, Wilfredo Lam, Xul Solar e Antonio Berni, não foi suficiente para que o episódio deixasse de ser compreendido como uma perda para a cultura nacional. Esse episódio é uma evidência do quanto essa obra possui um valor paradigmático, ao lado de outras pinturas e esculturas realizadas pelos artistas designados “modernistas". Na realidade, o modernismo brasileiro, cuja primeira fase compreende a produção realizada entre finais dos anos de 1910 e os anos de 1940, consolidou um lugar ímpar na história da cultura no Brasil. Suas principais obras foram, e ainda são, vistas como artefatos materiais capazes de cristalizar simbolicamente uma cultura nacional de valor internacional. A elas foram atribuídos não apenas valores artísticos, mas também valores culturais e políticos mais amplos, como o de símbolos identitários.

2 A glorificação do modernismo no Brasil é um processo que perpassa todo o século xx e que envolve um conjunto de agentes - críticos, historiadores, curadores de arte - e diversas práticas sociais, como o mercado de arte, as aquisições realizadas pelos museus e, ainda por vezes, uma política cultural explicita levada a cabo pelo Estado, em sua dimensão nacional ou regional. Em linhas gerais, pode-se dividir esse processo em três 
fases. O primeiro momento, que compreende o intervalo de 1917 a 1940, caracteriza-se pela construção de uma história da arte moderna no Brasil em que se toma como ponto de vista a fala dos próprios participantes do movimento. A segunda fase, que vai da década de 1940 até o final da década de 1970, pode ser entendida como o momento de institucionalização da crença no valor da arte moderna no Brasil, processo que contou com a chancela dos trabalhos produzidos no interior do sistema universitário, bem como das aquisições oficiais de acervos notórios de artistas modernistas. No final da década de 1970, inicia-se um momento de revisionismo crítico marcado pela emergência de diversos tipos de contestação sobre o caráter efetivamente moderno do modernismo brasileiro, sobre os limites formais desse movimento e ainda sobre a posição central de certos grupos e regiões do país na construção de um discurso canônico, ao mesmo tempo em que houve tentativas de se repensar, de maneira mais matizada, o alcance e a especificidade de tais produções no país.

\section{Os primeiros tempos modernistas}

3 As origens do modernismo no Brasil estão permanentemente em discussão. Tais contendas revelam não apenas dicotomias entre modalidades de interpretação e de definição do que se entende por modernismo, mas também clivagens regionais que envolvem grupos de intelectuais, universidades com prestígios hierarquicamente distintos, museus, galerias e colecionadores ${ }^{1}$.

4 No entanto, a visão mais difundida considera que o estopim do movimento modernista ocorreu em 1922 em São Paulo. Em fevereiro desse ano, organizou-se no Teatro Municipal de São Paulo - uma instituição central da conservadora elite paulistana inaugurada em 1914 - uma série de eventos literários, musicais e plásticos que recebeu o nome de Semana de Arte Moderna (em referência a modelos estrangeiros, notadamente à Semana de Deauville) ${ }^{2}$. Para muitos autores, esse episódio é considerado um divisor de águas na história da arte brasileira, um marco zero do modernismo nacional. Essa concepção do modernismo como movimento predominantemente paulista, defendida inicialmente pelos seus protagonistas, foi retomada e reafirmada em estudos publicados na década de 1970 (AMARAL, 1970; BRITO, [1958] 1974; ALMEIDA, [1961] 1976).

5 A adoção da "Semana de 22" como um marco resulta do processo de construção da memória do modernismo brasileiro, que contou inicialmente com os textos propagados pelos próprios intelectuais e artistas pertencentes ao círculo modernista. Eles não se configuraram como um grupo até 1917, quando a exposição de Anita Malfatti, artista paulista que retornava de seus estudos feitos na Alemanha e nos Estados Unidos ${ }^{3}$, exibiu obras que chocaram os meios locais. Seus vigorosos nus a carvão e, especialmente, suas pinturas expressionistas, as quais apresentavam um cromatismo livre e uma tematização incomum de figuras humanas - como imigrantes (O Japonês, 1915-1916, São Paulo, Instituto de Estudos Brasileiros) ou loucos (A boba, 1915-1916, Museu da Arte Contemporânea da Universidade de São Paulo) - foram mal recebidos por um público acostumado às estéticas naturalistas e pós-impressionistas então dominantes.

6 Nesse mesmo ano, em reação à exposição de Anita Malfatti, Monteiro Lobato, o mais importante crítico de São Paulo, publicou o artigo intitulado "Paranoia ou mistificação?", no qual expressava sua rejeição pelas vanguardas históricas, vistas como correntes opostas ao figurativismo naturalista ${ }^{4}$ (cf. CHIARELLI, 1995). A severa crítica 
propagada por Lobato contra as obras da artista, que considerava distorções de mau gosto, provocou a reação de jovens literatos e artistas visuais, como Oswald de Andrade, Menotti del Picchia e Emiliano Di Cavalcanti, os quais passaram a defendê-la nos jornais. Dessa feita, começaram a se reconhecer e a atuar como grupo, tendo como principal lastro institucional a imprensa. Ainda que São Paulo fosse nesse momento a cidade mais rica do país - graças ao capital oriundo das exportações de café, a um acelerado processo de modernização, intensificado por levas de imigrantes, e a um embrionário processo de industrialização -, possuía relativamente poucas instituições culturais. Dentre elas, destacavam-se a Faculdade de Direito; o Museu Paulista, fundado em 1895 e incorporado posteriormente à Universidade de São Paulo; a Pinacoteca do Estado de São Paulo, inaugurada em 1905 (único museu da cidade dedicado exclusivamente às belas artes); e o Liceu de Artes e ofícios, um espaço de formação de artistas que, como o nome indica, destinava-se mais às artes aplicadas do que às artes puras. Por isso, como observa o sociólogo Sergio Miceli, nesse período "em termos concretos, toda a vida intelectual era dominada pela grande imprensa, que constituía a principal instância de produção cultural da época e que fornecia a maioria das gratificações e posições intelectuais" (MICELI, [2001] 2005, p. 17). Os jornais e revistas ilustrados constituíam o lócus em que tais intelectuais se encontravam, expunham seus trabalhos e propagavam seus ideais. Foi por meio das publicações na imprensa paulistana que a primeira geração de modernistas aos poucos se impôs localmente. As críticas deflagradas por Lobato contra Anita Malfatti suscitaram, assim, respostas em sua defesa nos jornais: ao artigo assinado por Oswald de Andrade no Jornal do Commercio em 1918, somaram-se os textos de Menotti Del Picchia, publicado no Correio Paulistano em 1920, e de Mario de Andrade, no Jornal de Debates em $1921^{5}$.

7 Ainda que não estivessem reunidos em torno de princípios coesos capazes de gerar manifestos, se viam e eram vistos por seus adversários como "futuristas", em referência ao célebre Manifesto Futurista, do escritor italiano Filippo Tommaso Marinetti. Preocupados em superar tudo aquilo que viam como retrógrado na cultura brasileira, como a tradição agrária, regional e popular, além da acadêmica e parnasiana, buscavam o compasso com o cosmopolitismo irradiado pelas vanguardas europeias. Nesse projeto, construíam em suas obras uma imagem de São Paulo como cidade aberta à modernização, em constante mudança, livre do passado e em permanente marcha para o futuro. Nesse desejo de atualização imediata, São Paulo emergia como um "mito tecnicizado" (FABRIS, 1994a), lugar de ininterrupta destruição das tradições, ansiosa por todos os tipos de inovação, receptiva às novas linguagens artísticas e às transformações sociais, politicas e culturais caudatárias das ondas imigratórias. Mesmo se tais imagens correspondessem mais aos desejos desses "futuristas" do que à realidade cotidiana dos habitantes da metrópole, ainda hoje estão implantadas no imaginário que projeta a cidade como "carro-chefe da nação".

8 Assim, nesse momento, as produções dos "futuristas" não procuravam reivindicar as particularidades da cultura brasileira, mas bem o contrário: desejavam compassar a cultura nacional, vista como atrasada, às experiências internacionais, consideradas cosmopolitas e progressistas. Essa ambição encontra-se bem expressa no romance Pauliceia desvairada (1922), de Mário de Andrade, e no álbum Fantoches da meia-noite (1921), de Di Cavalcanti. Com efeito, as obras expostas na "Semana de 22" - com exceção das enviadas por Anita Malfatti e John Graz - não podiam ser tomadas nem como radicalmente modernas, devido ao predomínio das linguagens pós- 
impressionistas e neocoloniais, nem como eivadas de uma preocupação com a "cultura nacional" (AMARAL, 1970).

9 Foi ao longo da década de 1920, quando muitos artistas brasileiros usufruíram de longas estadias em Paris com vistas a aprimorar seus estudos, que, curiosamente, as particularidades da cultura brasileira passaram a lhes interessar. Em 1921, Antonio Gomide e Victor Brecheret aportaram em Paris, onde já se encontrava Vicente do Rego Monteiro; em 1923, chegaram Tarsila do Amaral, Oswald de Andrade, Anita Malfatti, Di Cavalcanti e Celso Antônio, entre tantos outros (BATISTA, 2012). É em Paris que Di Cavalcanti realiza os primeiros desenhos de mulatas - tema que se tornou emblemático de seu trabalho e foi diversas vezes explorado em suas obras até o fim de sua vida. Em sua autobiografia, ele explica que: “[....] Paris pôs uma marca na minha inteligência. Foi como criar em mim uma nova natureza e o meu amor à Europa transformou meu amor à vida em amor a tudo que é civilizado. E como civilizado comecei a conhecer minha terra" (DI CAVAlCANTI, [1955] 1995, p. 142).

10 Tarsila do Amaral é quem talvez melhor explicite essa transformação súbita de linguagem, temática e consciência. Em 1921, inscrita na Academie Julian, ela exercitouse em nus pós-impressionistas; em 1923, quando aluna de Léger, compôs uma de suas obras mais emblemáticas, A negra (1923, São Paulo, Museu de Arte Contemporânea da Universidade de São Paulo), considerada "pioneira de um estilo modernista brasileiro" (AMARAL, [1975] 2003, p. 97). Em uma carta escrita à família, a pintora assinala estar consciente do interesse que as culturas exógenas despertavam nos meios intelectuais franceses: “[...] Sinto-me cada vez mais brasileira: quero ser a pintora de minha terra. Como agradeço por ter passado na fazenda a minha infância toda. As reminiscências desse tempo vão se tornando preciosas para mim. Quero, na arte, ser a caipirinha de São Bernardo, brincando com bonecas de mato, como no último quadro que estou pintando. Não pensem que essa tendência é mal vista aqui. Pelo contrário. 0 que se quer aqui é que cada um traga contribuição do seu próprio país. Assim se explicam os sucessos dos bailados russos, das gravuras japonesas e da musica negra. Paris está farta de arte parisiense" (AMARAL, [1975] 2003, p. 78).

11 Com efeito, a experiência de Tarsila é considerada o exemplo da viagem artística ideal, um caso "paradigmático da relação entre condição abastada, aculturação francesa e alinhamento modernista" (DURAND, [1989] 2009, p. 77). Casada com o poeta modernista Oswald de Andrade e, assim como ele, beneficiária de uma considerável fortuna advinda do café e do capital imobiliário, Tarsila logrou inserir-se nos círculos internacionais da vanguarda constituídos em Paris por meio de inúmeras estratégias, como a participação como aluna nos ateliês dos já célebres Albert Gleizes, André Lhote e Fernand Léger; a formação de uma alentada coleção de obras modernistas, viabilizada pelo contato direto com os próprios artistas ou com seus representantes galeristas, como Léonce Rosemberg; e ainda o investimento na criação de sua própria imagem de pintora plenamente moderna, como bem evidencia seu autorretrato de 1923 (Rio de Janeiro, Museu Nacional de Belas Artes), em que porta um manteau de Paul Poiret, cuja fama de costureiro elegante, moderno e "exótico" assegurou às suas criações um capital simbólico explorado pela artista nesse quadro (MICELI, 2003).

12 A essa inserção estratégica da pintora na vanguarda cubista francesa, soma-se um outro dado também muito aclamado pela intelligentzia brasileira: a criação de uma série de obras modernas que dialogava com as vanguardas internacionais de seu tempo, mas a partir de elementos tidos como "nacionais". Essa "fase Pau-Brasil", como foi 
denominada, compreende as produções realizadas por Tarsila do Amaral na década de 1920. Em uma carta à pintora, Mário de Andrade, o líder intelectual do grupo modernista paulista, mostrava o quanto ele se preocupava com a possibilidade de os brasileiros se afastarem de sua missão, a saber, a de representarem seu país: "Tarsila, minha querida amiga/Cuidado! Fortifiquem-se bem de teorias e desculpas e coisas vistas em Paris. Quando vocês aqui chegarem, temos briga, na certa. Desde já, desafio vocês todos juntos, Tarsila, Osvaldo e Sergio para uma discussão formidável. Vocês foram a Paris como burgueses. Estão épatés. E se fizeram futuristas! hi!hi!hi! choro de inveja UI! Ui! Ui! Mas que viado! Mas é verdade que considero vocês todos uns caipiras em Paris. Vocês se parisianizaram na epiderme. Isso é horrível! Tarsila, Tarsila, volta para dentro de ti mesma. Abandona o Gris e o Lhote, empresários de criticismos decrépitos e de estesias de ardentes! Abandona Paris! Tarsila! Tarsila! Vem para a mata virgem, onde não há arte negra, onde não há também arroios gentis. Há MATA VIRGEM. Criei o matavirgismo. Sou matavirgista. Disso é que o mundo, a arte, o Brasil e minha queridíssima Tarsila precisam. [...] Um abraço muito amigo do Mário" (Mário de Andrade, in AMARAL, [1975] 2003, p. 369).

13 Ao longo da década de 1920, essa visão do modernismo como um movimento de valor nacional e internacional cujo ponto inicial seria a "Semana de 22" foi se constituindo como um dogma, principalmente graças ao espaço que seus membros cultivaram na imprensa da época, tornada uma espécie de arena de propagação dos ideais do grupo. Menotti del Picchia, um de seus mais fervorosos defensores, detinha uma coluna diária no Correio Paulistano, enquanto Oswald de Andrade possuía ampla liberdade para escrever no Jornal do Commercio, além do que era proprietário da importante revista 0 Pirralho. Não por acaso, a maior realização dos modernistas enquanto grupo, findada a "Semana de 22", foi a publicação da revista Klaxon, vitrine de sua produção literária, plástica e intelectual que circulou entre 1922 e 1923 (MORAES, 2011, p. 163-167).

14 Alçado à condição de primeiro movimento genuinamente brasileiro e compreendido como um grito da consciência nacional, o modernismo garantiu a certos grupos e a seus protagonistas um lugar de grande proeminência; eles tornaram-se, assim, símbolos culturais - e políticos-dos poderes de transformação oriundos das nações "periféricas". Andrea Giunta analisa a força das estratégias periféricas que permitiram a vários artistas latino-americanos e, em particular, ao movimento Pau-Brasil, que eclode com Tarsila do Amaral e Oswald de Andrade, apropriar-se das estruturas formais primitivas, deslocando o sentido da "outridade" para o centro do discurso das vanguardas. Ao fazê-lo, esses modernistas contribuíram ativamente para um discurso universalizante da modernidade (GIUNTA, 2011, p. 300). Discurso esse que, no caso das "modernidades periféricas" (SARLO, 1988), parecia possuir a força de uma ação libertadora. As periferias tornaram-se, enfim, partícipes dos movimentos culturais centrais, mas a partir de valores e estratégias que lhe eram próprios.

Se os anos 1920 foram o momento de efervescência do modernismo em formação, a década de 1930 pode ser considerada a época de maturação e oficialização do movimento. O governo de Getúlio Vargas (1937-1945), visando a se contrapor ao liberalismo e ao regionalismo que caracterizaram a Primeira República, levou a cabo uma política centralizadora que objetivava produzir um "novo homem brasileiro". Para tanto, a cultura e a educação tornaram-se dimensões prioritárias, responsáveis por moldar a "alma da nação" (SCHWARZTMAN, 1984). Uma série de políticas culturais foram implementadas no sentido de se promover a integração nacional por meio de símbolos 
que até hoje identificam os sinais de "brasilidade", tais como a feijoada", a capoeira e o samba: práticas anteriormente combatidas, posto que associadas ao passado escravista, foram então consideradas sinais da convivência pacífica entre raças e culturas, permitindo celebrar a "mestiçagem" como elemento nacional integrador (scHWARCZ, 1995).

No campo das artes e da arquitetura, o ministério liderado por Gustavo Capanema decidiu fazer da área da cultura um negócio de Estado, atribuindo-lhe um orçamento que permitia a realização de encomendas e criando uma intelligentzia, um corpo tecnicamente qualificado para dar vazão a suas realizações (MICELI, [2001] 2005). Inaugurou-se um campo frutífero de possibilidades para intelectuais, artistas e arquitetos - vários dentre eles de orientação modernista -, os quais foram chamados a participar de um regime claramente autoritário. 0 caso mais emblemático é o da sede do Ministério da Educação e Saúde, cuja construção devia materializar os discursos sobre a nação. Para tanto, abriu-se um concurso para escolha dos melhores projetos e o vencedor foi o arquiteto neocolonial Archimedes Memória. Esse fato desagradou o ministro, que desejava uma linguagem mais moderna. Capanema anulou o concurso e convidou o arquiteto e urbanista de orientação modernista Lucio Costa, cujo projeto havia sido inicialmente desclassificado. Formou-se então uma equipe composta por Affonso Reidy, Carlos Leão, Jorge Moreira e Oscar Niemeyer, a qual contou com a assessoria prestigiosa de Le Corbusier, arquiteto modernista franco-suíço que possuía então uma relativa projeção internacional. 0 edifício constitui uma primorosa síntese visual do modernismo brasileiro. Por um lado, absorve elementos do paradigma internacional defendido por Le Corbusier, como o uso de pilotis para liberar o piso térreo, de uma fachada em vidro, de uma planta livre e de brise-soleil, fatores associados a um discurso progressista voltado à celebração do futuro. Por outro lado, relê e reinsere uma suposta "tradição" arquitetônica brasileira na medida em que se vale de materiais como azulejos brancos e azuis - concebidos pelo pintor mais afamado da época, Candido Portinari - para revestir as paredes externas do prédio; nobres madeiras nacionais (como a sucupira) para a confecção do mobiliário; lioz ${ }^{8}$ português para revestir os pisos nobres e ainda gnaisse carioca para revestir as empenas - duas pedras muito empregadas pelos escultores barrocos cariocas. Tais elementos materializam a retomada imaginária de um certo passado vinculado ao barroco, de sorte que, nesse edifício, futuro e passado encontram-se interligados (WILLIAMs, 2001; CAVALCANTI, 2006).

17 Em seu interior, destaca-se o conjunto de pinturas murais encomendas a Candido Portinari, que consagrara-se em 1934 com a composição O Mestiço (1934, São Paulo, Pinacoteca do Estado de São Paulo), mostrando ser capaz de heroicizar tipos humanos populares, especialmente mestiços e negros. Essa assimilação visual de questões raciais alinhava-se com os discursos então vigentes junto a setores da intelectualidade nacional, e sua arte ganhou rapidamente a aprovação do Estado Novo, aderindo ao ideário governamental. Portinari realizou dez painéis para o Ministério, cada um figurando um dos momentos específicos dos diversos ciclos econômicos que constituem a trajetória da nação: Pau-Brasil, Borracha, Açúcar, Café, etc. Ao combinar elementos clássicos e modernos, utilizando-se da deformação e de elementos expressionistas, o artista criou tensões não apenas entre os planos compositivos mas também entre a ideologia trabalhista e racial propagada pelo governo, de um lado, e a figuração particular de heroísmo construída nessa série, de outro. $O$ pintor ousou ao representar 
os negros e mestiços como protagonistas da história do país: homens e mulheres anônimos, força de trabalho expropriada e vitimada (FABRIS, 1996).

Com o Estado Novo, o modernismo alcançou uma proeminência notável. Após o Ministério da Educação e Saúde, o Conjunto da Pampulha, construído entre 1942 e $1943^{9}$, também mobilizou grandes nomes da arquitetura e das artes plásticas. Realizado em Belo Horizonte, o projeto consagrou definitivamente Niemeyer e Portinari como expoentes, respectivamente, da arquitetura e da pintura modernista brasileira. Nos anos seguintes, seguiram-se outras encomendas de destaque, como o Parque do Ibirapuera, inaugurado em 1954 em São Paulo, e a cidade de Brasília, construída entre 1956 e 1960. Consagrado nacionalmente, o modernismo passou também a ser exportado como "imagem do país".

Durante o Estado Novo, em um contexto político de aproximação entre os Estados Unidos e a América Latina, fomentou-se uma série de eventos com o objetivo de elaborar uma imagem positiva do Brasil. Em 1940, foi realizada a exposição Portinari of Brazil no Museum of Modern Art (MoMA) e, em 1943, a importantíssima Brazil Builds, também ocorrida no MOMA ${ }^{10}$. Idealizada por Philipp Goodwin, curador da instituição, essa exposição contou com um catálogo que se tornou uma referência internacional sobre a arquitetura brasileira, representada por meio de imagens de edificações barrocas e construções modernistas. É importante lembrar também a participação do país na Feira Mundial de Nova York, em 1939-1940, com um pavilhão projetado por Lucio Costa e Oscar Niemeyer. Na década seguinte, Niemeyer e Portinari foram consagrados definitivamente no âmbito internacional ao colaborarem na construção da sede das Nações Unidas: o arquiteto carioca foi um dos coautores do projeto arquitetônico e o pintor paulista realizou dois imensos painéis representando a Guerra e a Paz. A batalha para expandir e consolidar o modernismo brasileiro havia sido vencida.

O modernismo se impôs como cânon nacional incontestável até o ingresso das linguagens construtivas no país durante os anos 1950. A introdução das correntes abstratas, especialmente com a inauguração da Bienal de São Paulo em 1951, colocou em cheque o predomínio das linguagens figurativas constitutivas do programa modernista que se propagara no Brasil desde os anos 1920. Ao longo da década de 1950, presenciou-se a ascensão do abstracionismo geométrico (mais conhecido no Brasil pelo nome de concretismo) como uma nova vanguarda nacional (BRITO, 1985; COUTO, 2004). A ascensão da arte abstrata trouxe consigo a desvalorização da produção das gerações anteriores e, com isso, uma certa marginalização das obras e dos artistas modernistas.

\section{A consagração histórica do modernismo}

21 Em 1952, no trigésimo aniversário da "Semana de 1922", pouco havia a se comemorar. No entanto, no momento em que o modernismo recalcitrava, entrou em curso um processo que culminará em sua legitimação. A origem dessa consagração histórica deuse não tanto no campo artístico, dominado pela força dos concretistas, mas no acadêmico. Em 1953, Antonio Candido de Mello e Souza - um dos mais respeitados intelectuais brasileiros, casado com a crítica e professora de estética Gilda de Mello e Souza, prima de Mário de Andrade - desenvolveu, em um ensaio intitulado "Literatura e cultura de 1900 a 1945", uma noção que já se encontrava esboçada nos trabalhos de Mario de Andrade. Ao defender um programa de valorização da especificidade da cultura local, Mario de Andrade havia reestabelecido certas premissas comuns ao 
romantismo brasileiro, uma espécie de estética oficial do Segundo Reinado brasileiro (1840-1889). Para Antonio Candido de Mello e Souza, a dialética entre o localismo e o cosmopolitismo destacada por Mario de Andrade é um topos de longa duração e constitui a "lei de evolução da nossa vida espiritual" (souzA, [1965] 2000, p. 101)11. O romantismo e o modernismo são por ele considerados os dois momentos culminantes desse processo. No entanto, enquanto o romantismo brasileiro não foi capaz de romper completamente com o modelo europeu, o modernismo promoveu uma efetiva autonomia cultural ao incentivar a "libertação de uma série de recalques históricos, sociais, étnicos, que são trazidos triunfalmente à tona da consciência literária. Este sentimento de triunfo, que assinala o fim da posição de inferioridade no diálogo secular com Portugal e já nem o leva mais em conta define a originalidade própria do Modernismo na dialética do geral e do particular" (souzA, [1953] 2000, p. 110). De acordo com ele, essa transformação foi promovida por intermédio da reinterpretação de legados históricos - heranças em tudo distantes da Europa e difíceis de serem superadas pelo país, como a escravidão, a mestiçagem e a relação com natureza e a paisagem. Para o autor, é com o modernismo que as "nossas deficiências, supostas ou reais são reinterpretadas como superioridades" e, finalmente, "o mulato e no negro são definitivamente incorporados como temas de estudo, inspiração, exemplo. 0 primitivismo é agora fonte de beleza e não mais empecilho à elaboração da cultura. Isso na literatura, na pintura, na música, nas ciências do homem" (CANDIDo, [1953] 2000, p. 110).

Por sua importância literária, estética e também política, a obra de Antonio Candido de Mello e Souza desempenhou um papel fundamental na veiculação da concepção do modernismo como um modelo canônico para o Brasil. Para tanto, também contribuiu a posição que ele viria a ocupar na cultura brasileira como docente de grande destaque na Universidade de São Paulo, onde formou gerações de professores, pesquisadores e críticos, ainda hoje atuantes nos campos artísticos e literários. Como já se notou, houve uma continuidade entre a geração modernista da década de 1920 e as análises de Antonio Candido Mello e Souza, bem como de outros intelectuais que despontaram nos anos 1940 reunidos em torno da revista Clima (PONTES, 1998; PASSIANI, 2003). O fato de que vários dos expoentes dessa revista, como Candido, Gilda de Mello e Souza, Paulo Emilio Sales Gomes e Décio de Almeida Prado, tenham sido professores da Universidade de São Paulo, uma das mais importantes do país, possibilitou o que Pierre Bourdieu chama de "imposição da taxionomia legítima" dos campos literário e artístico (BOURDIEU, [1992] 1996, p. 253). Realizadas no interior do sistema universitário e tomadas como referência de qualidade, rigor e erudição, as obras desses intelectuais contaram, assim, com a legitimação concreta e simbólica outorgada pela instituição.

Após a publicação do artigo de Antonio Candido de Mello e Souza, seguiu-se uma série de obras de teor semelhante, nas quais é possível identificar topos reiterados, tais como a centralidade da inteligentzia paulista na difusão do modernismo em escala nacional; a "Semana de 1922" como marco fundador; e a capacidade do movimento em sincronizar a produção cultural brasileira com a dos mais importantes centros de seu tempo, superando o suposto atraso histórico do Brasil, e concomitantemente em exaltar as particularidades locais, de matrizes populares e mestiças, atrelando-as a um hipotético resgate da cultura nacional.

24 Para além desses elementos mais substantivos, outro aspecto comum a essas narrativas é o seu caráter teleológico. Elas tendem a alinhavar cronologicamente diversos fatos 
históricos de sorte a estabelecer continuidades entre a formação do grupo modernista em 1917, a "Semana de 22" e outros episódios mais recentes, como a fundação, em São Paulo, do Museu de Arte Moderna (MAM), em 1948, e do Museu de Arte de São Paulo (MASP), em 1949. Tal perspectiva encontra-se em publicações até hoje tidas como obras de referência para a história da arte brasileira, como História do modernismo no Brasil, de Mário da Silva Brito, publicada originalmente em 1958 (BRITo, [1958] 1974); e De Anita ao Museu, de Paulo Mendes de Almeida, cuja primeira edição é de 1961 (ALMEIDA, [1961] 1976). Frequentemente lidas por seu suposto teor informativo, essas obras estão inteiramente ancoradas em um partido estético previamente definido que apresenta esses dois museus como fruto das ações realizadas pelos modernistas desde a década de 1920.

Paralelamente ao surgimento dessas obras, que hoje fazem parte da historiografia modernista, vale assinalar um outro tipo de publicação lançado nesse período, menos analítico, mas igualmente relevante para a disseminação generalizada da importância da geração de 1920: os testemunhos e as memórias dos protagonistas da primeira geração modernista. Em 1954, foi publicado o Testamento de Mario de Andrade e outras reportagens, de Francisco de Assis Barbosa (BARBOSA, 1954); em seguida, em 1955, o livro de memórias de Di Cavalcanti, intitulado Viagem da Minha Vida: o testamento da alvorada (DI CAVAlCANTI, [1955] 1995); dois anos depois, Manuel Bandeira publicou Itinerário a Pasárgada (BANDEIRA, 1957), de teor autobiográfico; e, no ano seguinte, uma coletânea de cartas escritas por Mário de Andrade foi editada com o título de Cartas a Manuel Bandeira (ANDRADE, BANDEIRA, 1958; a respeito da correspondência entre os dois escritores, cf. MORAES, 2000). A publicação desse material - incentivada pelos mais jovens defensores do movimento, como Antonio Candido e Gilda de Mello e Souza - constituiu um passo decisivo para a legitimação do ponto de vista dos próprios modernistas dos anos $1920 \mathrm{e}$ 1930 acerca de sua importância para a cultura nacional (COELHO, 2012).

Ao longo da década de 1960, não apenas novas publicações adensaram a perspectiva triunfal do modernismo, mas também certas ações, notadamente as que foram levadas a cabo pelo Estado, somaram-se a esse processo de consagração do movimento. Os muitos estudos existentes sobre a intervenção do Estado no campo das artes plásticas durante os anos autoritários, de 1964 a 1988, (cf., por exemplo, RIDENTI, 2000; NAPOLITANO, 2011) geralmente priorizam a análise de obras e artistas sob o prisma da resistência, de sorte a identificar nas políticas oficiais diretrizes voltadas somente a cercear e a obstaculizar a liberdade artística. No entanto, é importante salientar que a interferência do Estado no campo das artes plásticas não se restringiu apenas a uma dinâmica negativa e simplesmente coercitiva de um Estado censor; pode-se perceber também uma agenda construtiva de promoção de determinadas tendências, grupos e/ ou linguagens artísticas, ainda que subjugada a orientações ideológicas de caráter autoritário (DURAND, [1989] 2009; ORTIZ, 1988).

Um elemento essencial para se perceber isso é o processo de aquisição de coleções modernistas, praticamente em sua totalidade patrocinado pelo poder púbico. Em 1968, por intermédio de Antonio Candido de Mello e Souza, a Universidade de São Paulo adquiriu a coleção de artes visuais de Mário de Andrade, acompanhada pelo arquivo pessoal do escritor - que reunia um impressionante acervos de cartas trocadas com personalidades de seu tempo -, bem como de sua biblioteca (BATISTA, LIMA, 1998). No ano seguinte, o Estado de São Paulo fez a aquisição da coleção, do arquivo e da biblioteca de Guilherme de Almeida, outro grande escritor e colecionador modernista ${ }^{12}$. A compra de 
tais conjuntos documentais evidencia uma preferencia estatal no sentido de consagrar as memórias e as produções dos modernistas, posto que não havia medidas equivalentes em termos de aquisições, mecenato ou patrocínio direto aos artistas então vivos (BRITO, [1975] 2005). Vale considerar o efeito póstumo produzido por tais aquisições na medida em que a sua dimensão pública implica um acesso permanente e renovado a tais fontes, suscitando continuamente pesquisas (acadêmicas ou não) sobre essas coleções, o que amplia, assim, sua importância e sua legitimidade até os dias de hoje (COELHO, 2012).

Também nessa época, entre meados da década de 1960 e de 1970, consolidou-se um mercado de arte no Brasil, graças principalmente ao apoio indireto do Estado, que estabeleceu acordos com sistema bancário nacional no sentido de facultar linhas de crédito específicas para aquisição de obras. Nesse período, conhecido como "milagre econômico", as obras de arte adquiriram um caráter manifesto de investimento, participando da constituição de um mercado de bens simbólicos no país (ORTIZ, 1988). Inicialmente benemerente, esse sistema alimentado por leilões de arte assumiu aos poucos um caráter nitidamente comercial, e os preços nele praticados passaram a servir de baliza orientadora para as galerias privadas, então em plena proliferação.

Nesse contexto, as obras dos artistas modernistas brasileiros paulatinamente se consolidaram como as mais cobiçadas mercadorias disponíveis. No final da década de 1960, em uma clara estratégia comercial, marchands atuantes em São Paulo adquiriram a preços baixos obras de pintores modernistas que naquele momento eram pouco valiosas e estavam relativamente esquecidas e as estocaram. Concomitantemente, investiram em construir uma história da pintura brasileira a partir do material que detinham, lançando livros dedicados aos artistas em questão e exibindo suas obras em suas próprias galerias (DURAND, [1989] 2009; BUENO, 2012). Esse período de valorização mercadológica da produção modernista coincidiu com o da morte de seus mais notáveis membros (Segall faleceu em 1957; Pancetti, em 1959; Portinari e Guignard, em 1962; Anita Malfatti, em 1964; Vicente do Rego Monteiro, em 1970; e Tarsila do Amaral e Flávio de Carvalho, em 1973), o que acentuou a raridade de suas produções, posto que datadas e limitadas, e aumentou o valor dessas obras em um mercado caracterizado pela circulação de bens restritos.

Em 1972, no cinquentenário da Semana de Arte Moderna, o modernismo atingira sua consagração absoluta, chancelado pela crítica, pela universidade, pelo mercado, pelos museus, pelos colecionadores, e, mesmo que indiretamente, pelo Estado Nacional. Ao longo da década de 1970, vários de seus mais destacados membros foram temas de estudos monográficos rigorosos, realizados por pesquisadores reputados, geralmente vinculados à universidade. Essas obras logo foram publicadas e constituem ainda hoje os principais livros de referência sobre cada um desses artistas, como Portinari, pintor social, mestrado defendido por Annateresa Fabris em 1975 (FABRIS, [1975] 1990), Tarsila, sua obra e seu tempo, doutorado defendido por Aracy Amaral em 1976 (AMARAL, [1975] 2003) e Anita Malfatti e o início da arte moderna no Brasil, mestrado defendido por Marta Rossetti Batista em 1980 (BATISTA, [1980] 2006). Reconhecidos enquanto grupo, os modernistas foram então compreendidos como singularidades artísticas, potências criativas individualizadas. O ciclo de consagração se completara. 


\section{Modernismo em disputa:}

31 As críticas a esse fenômeno não tardaram a surgir. Já em 1975, em um importante artigo intitulado "Análise do circuito", Ronaldo Brito apontou os limites e os vícios da relação entre arte e mercado no Brasil durante o início da década de 1970 (BRITO, [1975] 2005). Contrastando com o tom otimista e ufanista que predominava nos discursos sobre o crescimento do mercado consumidor de artes - visto como um dos sinais do "milagre econômico do país" -, ele expôs seu caráter restrito e elitista. Os críticos e historiadores também não ficaram ilesos à reprovação: naquele momento, mais do que cumprirem suas funções com independência, eram os principais responsáveis pela "descoberta" de autores e artistas esquecidos no passado, inscrevendo-os em uma tradição cultural nacional e construindo assim uma história da arte brasileira conduzida não por seus aspectos formais e estéticos, mas pelos interesses das galerias que representavam (BRITO, [1975] 2005, p. 58).

Ronaldo Brito voltou a escrever diversas vezes sobre os limites do modernismo brasileiro, construindo, ao longo de sua produção, um arcabouço interpretativo refratário à historiografia até então dominante. A rigor, para Brito, bem como para a geração que lhe sucedeu e que hoje detém uma posição de prestígio na crítica cultural nacional, as primeiras produções modernistas não foram propriamente modernas. Por estarem incumbidas de representar uma "cultura genuinamente nacional", consistiram antes em um "rito de passagem para a modernidade". E o fizeram "paradoxalmente às custas da conquista cultural moderna por excelência: a autonomia da experiência do eu lírico moderno e sua entrega total à aventura da obra" (BRITO, [1975] 2005, p. 137). Em seu entender, apenas na década de 1950, com o triunfo das linguagens abstratas no país (o concretismo) e, em especial, com a internacionalização promovida com as Bienais de Arte de São Paulo, é que se configurou uma consciência estética propriamente moderna no Brasil (BRITO, 1985).

Assinala-se assim uma interessante contradição: o que parecia ser a força cultural do primeiro modernismo - a sua capacidade de plasmar uma arte concomitantemente nacional e moderna - é também o seu próprio limite. Para autores como Ronaldo Brito, Rodrigo Naves (NAVES, 1996) e mesmo Tadeu Chiarelli (CHIARELLI, 2012), a geração modernista da década de 1920, ao responder às necessidades ideológicas daquele momento, foi compelida a representar em suas obras uma suposta "realidade nacional". Esses artistas mantiveram-se assim presos a um esquema tradicional de representação, com referentes precisos, de sorte a esboçar uma concepção quase narrativa de pintura. Como afirma Brito, as telas dessa primeira geração "significam muito"; seus criadores estiveram presos a uma retórica social e humana que não lhes permitiu tomar o espaço da tela como plenamente autônomo, um campo de pesquisas eminentemente formais (вRITO, 1985, p. 13). Diferindo do modernismo francês, do qual se sentiam herdeiros distantes, os modernistas brasileiros se limitaram ao tema e à sujeição da pintura a um conteúdo. Na tela Cinco moças de Guaratinguetá, de Di Cavalcanti - uma releitura de Demoiselles d'Avignon de Pablo Picasso -, por exemplo, o tema da prostituição e do nu feminino parece ter inspirado o artista mais do que a dissolução da perspectiva que fez da obra de Picasso um marco na história da arte. Da mesma forma, Tarsila do Amaral, na época em que era aluna do ateliê de Léger, utilizou como referência Paysages animés, a série menos audaciosa e mais figurativa de seu mestre, sem conservar sua perspectiva crítica em relação à modernidade (MICELI, 2003). No entanto, convém notar que as 
críticas ao caráter pouco moderno do modernismo brasileiro estão balizadas em uma perspectiva teórico-metodológica particular, estabelecida notadamente por Clement Greenberg $^{13}$. Nela, privilegia-se a auto-referencialidade como critério de valor, excluindo as injunções sociais, históricas e políticas em que as obras se inserem. Além disso, há nessa abordagem uma evidente preferência por certas modalidades artísticas, como a pintura e a escultura, o que significa a exclusão a priori de certos movimentos e práticas artísticas, como o art nouveau, o art déco, o design e a moda, ou ainda de outras correntes artísticas de caráter figurativo, como o surrealismo. Finalmente, ela toma como exemplar a lógica de desenvolvimento dos campos artísticos francês e norte-americano, abstraindo os contextos e as condições em que eles se desenvolveram e fazendo dessas experiências modelos abstratos e universais a serem seguidos por países cuja vida artística possui uma história própria e frequentemente distinta das apontadas como exemplares.

No caso brasileiro, esse último aspecto é decisivo. Segundo a historiadora da arte Annateresa Fabris, ainda que as obras dos modernistas não possam ser consideradas modernas de acordo com os prismas defendidos pelo paradigma greenbergniano, de um outro ponto de vista, elas o foram, na medida em que produziram uma consciência estética e cultural nova e radical para os meios locais (FABRIS, 1994b). Assim, é possível pensar que tenha havido no Brasil uma vanguarda antes do modernismo ou, ainda melhor, um modernismo que se afirmou não pelas potencialidades das linguagens artísticas em vias de autonomização, mas pelas estratégias de intervenção coletivas e pela relação com o público que visava provocar. Como afirma: "Paradoxal vanguarda a nossa, dividida entre passado e presente, ainda incerta sobre o significado da arte moderna, polêmica em relação a algumas de suas propostas mais extremistas, mas assim mesmo consciente da necessidade de uma ação violenta se quisessem imprimir novos ritmos à criação cultural no Brasil" (FABRIS, 1994a, p. 24-25).

Além das divergências no que tange a própria definição do modernismo e a conciliação da experiência histórica particular do caso brasileiro com conceitos que se pretendem universais, outras tensões marcam hoje o debate historiográfico. Dentre elas, a questão geopolítica que perpassa as narrativas modernistas. Trata-se de questionar a crença amplamente disseminada de que o modernismo brasileiro é um produto originalmente paulista que teria se propagado para todo o Brasil a partir desse epicentro. Alguns estudos publicados nos últimos anos insistem na importância das artes gráficas e de algumas obras plásticas realizadas no Rio de Janeiro na virada do século XIX para o século xx no que tange à formação de uma nova visualidade compassada com as transformações urbanas em vigor na capital da Primeira República - concepção que teria antecedido a consciência moderna urbana reivindicada pelos defensores da "Semana de 22" (VELLOSO, 1996; HERKENHOFF, 2002). Outros estudos apontam o quanto as narrativas tendem a desconhecer e a desvalorizar a dinâmica própria de produção e circulação de obras em vigor em outras capitais regionais (BULHÕES, 1995; TEJo, 2012).

É preciso ainda mencionar os muitos trabalhos acadêmicos que têm proposto uma reinterpretação das críticas disparadas pelos modernistas de São Paulo contra as práticas acadêmicas (COLI, 2005; MIGLIACCIO, 2000; MARQUES, 2001; CHIARELLI, 2010; DAZZI, 2011). As pesquisas atuais sobre a produção realizada ao longo do século XIX e no início do século xx no Brasil demonstram ser incorreta a tese de que a academia teria permanecido avessa às intensas transformações políticas e sociais ocorridas após a proclamação da República, em 1889. Tais análises têm ampliado consideravelmente a 
compreensão do significado histórico do termo "moderno" no Brasil, contestando o monopólio reivindicado pelos estudos canônicos sobre modernismo realizado nas décadas de 1970 e 1980.

Tais contendas em relação às origens, às datas, aos locais e aos sentidos do que é ou não é moderno no Brasil trazem à tona a vitalidade e centralidade desse tema para a arte e a cultura do país. Mais do que resolver tais impasses, parece-nos melhor mencionar Pierre Bourdieu, que caracteriza a arte moderna justamente como uma luta permanente entre os membros do campo artístico pelo direito de impor sua própria definição do que é arte e de quem é artista (BourdiEu, [1992] 1996, p. 255-281). O conceito de modernismo não implica assim um estilo único, facilmente identificável por meio de características formais ou históricas precisas, com origens e mestres inquestionáveis. Antes, trata-se de um termo em disputa cujos sentidos específicos são reivindicados por cada um dos grupos, artistas, críticos e historiadores inseridos nesse universo concorrencial - todos eles investidos de confiança em suas próprias crenças, de paixão pelo que fazem e de incertezas quanto às vitórias futuras.

- wiLliams, 2001: Daryle Williams, Culture Wars in Brazil: The First Vargas Regime, 1930-1945, Durham (VA), 2001.

\section{BIBLIOGRAFIA}

- ALMeIDA, (1961) 1976: Paulo Mendes de Almeida, De Anita ao museu, São Paulo, (1961) 1976.

- AMARAL, 1970: Aracy Amaral, Artes plásticas na Semana de 22, São Paulo, 1970.

- AMARAL, (1975) 2003: Aracy Amaral, Tarsila, sua obra e seu tempo, São Paulo, (1975) 2003.

- AMARAL, 1998: Aracy Amaral, Artes plásticas na Semana de 22, São Paulo, 1998.

- ANDRADE, BANDEIRA, 1958: Mário de Andrade, Manuel Bandeira, Cartas de Mário de Andrade a Manuel Bandeira, Rio de Janeiro, 1958.

- BANDEIRA, 1957: Manuel Bandeira, Itinerário de Pasárgada: de poetas e de poesia, Rio de Janeiro, 1957.

- BARBOSA, 1954: Francisco de Assis Barbosa, Testamento de Mário de Andrade e outras reportagens, Brasília, 1954.

- BATISTA, 1972: Marta Rossetti Batista, Brasil: I tempo Modernista, 1917-1929, São Paulo, 1972.

- BATISTA, (1985) 2006: Marta Rossetti Batista, Anita Malfatti: no tempo e no espaço, São Paulo, (1985) 2006.

- BATISTA, LIMA, 1998: Marta Rossetti Batista, Yone Soares de Lima, Coleção Mário de Andrade: Artes plásticas, São Paulo, 1998.

- BATISTA, 2012: Marta Rossetti Batista, Os artistas brasileiros na Escola de Paris: anos 1920, São Paulo, 2012.

- BOURDIEU, (1992) 1996: Pierre Bourdieu, As regras da arte: gênese e estrutura do campo literário, São Paulo, 1996 [ed. fr.: Les Règles de l'art : genèse et structure du champ littéraire, Paris, 1992]. 
- BRITO, (1958) 1974: Mário da Silva Brito, História do modernismo brasileiro, 1, Antecedentes: a Semana de Arte Moderna, São Paulo, (1958) 1974.

- BRITO, 1983: Ronaldo Brito, “A semana de 22: o trauma do moderno”, in Sérgio Tolipan et al., Sete ensaios sobre o modernismo, Rio de Janeiro, 1983, p. 13-18.

- BRITO, 1985: Ronaldo Brito, Neoconcretismo: vértice e ruptura do projeto construtivo brasileiro, Rio de Janeiro, 1985.

- BRITO, (1975) 2005: Ronaldo Brito, “Análise do circuito”, in Ronaldo Brito, Experiência crítica, Sueli de Lima E., São Paulo, 2005, p. 53-63 [ed. orig. in Malasartes, 1, 1975].

- BUENo, 2012: Maria Lucia Bueno, "Arte e mercado no Brasil em meados do século xx", in Maria Lucia Bueno, Sociologia das Artes Visuais no Brasil, São Paulo, 2012, p. 75-95.

- BULHÕES, 1995: Maria Amélia Bulhões E., Artes plásticas no Rio Grande do Sul: pesquisas recentes, Porto Alegre, 1995.

- CAVALCANTI, 2006: Lauro Cavalcanti, Moderno e brasileiro: a história de uma nova linguagem na arquitetura (1930-60), Rio de Janeiro, 2006.

- CHIARELLI, 1995: Tadeu Chiarelli, Um jeca nos vernissages: Monteiro Lobato e o desejo de uma arte nacional no Brasil, São Paulo, 1995.

- CHIARELLI, 2010: Tadeu Chiarelli, “De Anita à academia”, in Novos Estudos, 88, 2010, p. 113-132.

- CHIARELLI, 2012: Tadeu Chiarelli, Um modernismo que veio depois: arte no Brasil, primeira metade do século Xx, São Paulo, 2012.

- COELHO, 2012: Frederico Coelho, A semana sem fim: celebrações e memória da Semana de Arte Moderna de 1922, Rio de Janeiro, 2012.

- COLI, 2005: Jorge Coli, Como estudar a arte brasileira do século XIX?, São Paulo, 2005.

- COUTO, 2004: Maria de Fatima Morethy Couto, Por uma vanguarda nacional: a crítica brasileira em busca de uma identidade artística (1940-1960), São Paulo, 2004.

- couto, 2012: Maria de Fatima Morethy Couto, “Arte engajada e transformação social: Hélio Oiticica e a exposição Nova Objetividade Brasileira", in Estudos Históricos, 25/49, janeiro-junho de 2012, p. 71-87.

- CYPRIANO, 2012: Fabio Cypriano, : O Banco de dados do Itaú Cultural: sobre o passado e o futuro", in Observatório Itaú Cultural, 13, 2013, disponível em: http://d3nv1jy4u7zmsc.cloudfront.net/wpcontent/uploads/2013/01/Revista-Observat\%C3\%B3rio-IC-n.13.pdf (Acesso em: 28 novembro 2013).

- DAzzI, 2011: Camila Dazzi, "Pôr em prática a Reforma da antiga Academia”: a concepção e a implementação da reforma que instituiu a Escola Nacional de Belas Artes em 1890, tese, Universidade Federal do Rio de Janeiro, 2011.

- Di CAVAlCANTI, (1955) 1995: Emiliano Di Cavalcanti, Viagem da minha vida (memórias), Rio de Janeiro, (1955) 1995.

- DURAND, (1989) 2009: José Carlos Durand, Arte, privilégio e distinção: artes plásticas, arquitetura e classe dirigente no Brasil, 1855/1985, São Paulo, (1989) 2009.

- FABRIS, 1990: Annateresa Fabris, Portinari, pintor social, São Paulo, 1990.

- FABRIS, 1994a: Annateresa Fabris, O futurismo paulista: hipóteses para o estudo da chegada da vanguarda ao Brasil, São Paulo, 1994. 
- FABRIS, 1994b: Annateresa Fabris, Modernidade e modernismo no Brasil, Campinas, 1994.

- FABRIS, 1996: Annateresa Fabris, Candido Portinari, São Paulo, 1996.

- FIALHo, 2012: Ana Letícia Fialho, “'Economias' das exposições de arte contemporânea no Brasil: notas de uma pesquisa", in Lia Calabre E., Políticas culturais: pesquisa e formação, São Paulo/Rio de Janeiro, 2012.

- FONSECA, 1997: Maria Cecília Londres Fonseca, O patrimônio em processo: trajetória da politica federal de preservação no Brasil, Rio de Janeiro, 1997.

- GIUNTA, 2011: Andrea Giunta, Escribir las imágenes: ensayos sobre arte argentino y latinoamericano, Buenos Aires, 2011.

- HERKENHOFF, 2002: Paulo Herkenhoff, Arte brasileira na coleção Fadel: da inquietação do moderno à autonomia da linguagem, Rio de Janeiro, 2002.

- MARQUeS, 2001: Luiz Marques, 30 Mestres da Pintura no Brasil: 30 anos Credicard, São Paulo, 2001.

- MARTINS, 2002: Carlos Ferreira Martins, "Construir uma arquitetura, construir um país”, in Brasil: da Antropofagia à Brasília, 1920-1950, Jorge Schwartz E., (cat. expo., São Paulo, Museu de Arte Brasileira, 2002-2003), São Paulo, 2002, p. 373-384.

- MICELI, 2003: Sergio Miceli, Nacional estrangeiro: história social e cultural do modernismo artístico em São Paulo, São Paulo, 2003.

- MICELI, (2001) 2005: Sergio Miceli, Intelectuais à brasileira, São Paulo, (2001) 2005.

- Migliaccio, 2000: Luciano Migliaccio, “O século XIX”, in Mostra do Redescobrimento: arte do Século XIX, Nelson Aguilar E., (cat. expo., São Paulo, Parque Ibirapuera, 2000), São Paulo, 2000, p. 36-217.

- MORAES, 2000: Marco Antonio Moraes E., Correspondência Mário de Andrade \& Manuel Bandeira, São Paulo, 2000.

- MORAES, 2011: Rubens Borba de Moraes, Testemunha ocular (recordações), Brasília, 2011.

- NAPOLITANO, 2011: Marcos Napolitano, Coração Civil: arte, resistência e lutas culturais durante o regime militar brasileiro (1964-1980), tese, Universidade de São Paulo, 2011.

- NAVES, 1996: Rodrigo Naves, A forma difícil: ensaios sobre a arte brasileira, São Paulo, 1996.

- ORTIZ, 1988: Renato Ortiz, A moderna tradição brasileira: cultura brasileira e indústria cultural, São Paulo, 1988.

- PASSIANI, 2003: Enio Passiani, Nas trilha do Jeca: Monteiro Lobato e a formação do campo literário no brasil, São Paulo, 2003.

- PONTES, 1998: Heloisa Pontes, Destinos mistos: os críticos do grupo Clima em São Paulo, 1940-68, São Paulo, 1998.

- RIDENTI, 2000: Marcelo Ridenti, Em busca do povo brasileiro: artistas de Revolução, do CPC à Era da TV, Rio de Janeiro/São Paulo, 2000.

- RUBiNO, 1992: Silvana Rubino, As fachadas da história, dissertação de mestrado, Universidade Estadual de Campinas, 1992.

- SARLO, 1988: Beatriz Sarlo, Una modernidad periférica. Buenos Aires 1920 y 1930, Buenos Aires, 1988.

- schwarTZMAn, 1984: Simon Schwartzman et al., Tempos de Capanema, São Paulo/Rio de Janeiro, 1984. 
- SCHWARCZ, 1995: Lília Schwarcz, “Complexo de Zé Carioca. Notas sobre uma identidade mestiça e malandra”, in Revista Brasileira de Ciências Sociais, 10/29, outubro 1995, p. 6-29.

- SouZA, (1953) 2000: Antonio Candido de Mello e Souza, “Literatura e cultura de 1900 a 1945", in

Literatura e sociedade, São Paulo, (1953) 2000.

- TEJo, 2012: Cristiana Tejo et al., Uma historia da arte?, Recife, 2012.

- Velloso, 1996: Mônica Pimenta Velloso, Modernismo no Rio de Janeiro: Turunas e Quixotes, Rio de Janeiro, 1996.

\section{NOTAS}

1. O Brasil é um país complexo, composto por estados com relativa autonomía. No entanto, os principais recursos estão concentrados nas regiões Sudeste e Sul; nesse sentido, sublinha-se a concentração do mercado da arte em cidades como São Paulo e Rio de Janeiro, as quais tendem a competir pelo título de "capital artística e intelectual" do país, a despeito da importância da produção crítica e historiográfica de outros estados. Sobre o campo artístico brasileiro, os museus e as políticas públicas, cf. FIALHO, 2012; sobre a concentração de exposições e curadores em São Paulo e no Rio de Janeiro, cf. CYPRIANO, 2012.

2. A ideia de usar a Semana de Deauville como modelo para a Semana de Arte Moderna de 1922 foi uma sugestão de Marinette Prado, esposa de Paulo Prado, um rico intelectual de São Paulo e também um dos mecenas da "Semana de 22". De acordo com o seu depoimento a Aracy Amaral, a Semana de Deauville, que existia desde o século XIX, ocorria durante o verão e reunia exposições de arte, de moda, etc. (cf. AMARAL, 1998, p. 128-129).

3. Anita Malfatti estudou artes plásticas com Fritz Burger e Lovis Corinth em Berlim entre $1910 \mathrm{e}$ 1914, quando retornou ao Brasil após o início da Primeira Guerra Mundial. No ano seguinte, sempre contando com o apoio e com a ajuda financeira de sua família, foi para Nova York dar sequência à sua formação. Estudou inicialmente na Art Students League e, em seguida, com Homer Bross, na Independent School of Art, onde ficou até o seu retorno definitivo ao Brasil, em 1917 (BATISTA, [1985] 2006).

4. Monteiro Lobato, “A Propósito da Exposição Malfatti”, in O Estado de S. Paulo, 20 de dezembro de 1917.

5. Vários dos primeiros artigos escritos pelos modernistas foram publicados nos livros de Marta

R. Batista (BATISTA, 1972) e Mário da Silva Brito (BRITo, [1958] 1974).

6. O pau-brasil, uma espécie vegetal bastante comum no momento da chegada dos colonizadores portugueses ao Novo Mundo, deu nome ao país. O uso dessa expressão pelos modernistas brasileiros revela, assim, a importância que eles atribuíam às questões "nativas".

7. A feijoada, prato tradicional consumido pelos escravos no Brasil, é composta de feijão e pedaços de carne de porco misturados com arroz (introduzido no século XIX por imigrantes japoneses) e couve (uma planta indígena). Durante o governo de Getúlio Vargas, ela foi considerada "o prato típico nacional", pois permitia celebrar a noção de mestiçagem defendida pelo regime.

8. Pedra calcária branca utilizada em esculturas e obras arquitetônicas; também pode ser usada como material de revestimento.

9. O Conjunto da Pampulha, situado às margens de um lago artificial a $18 \mathrm{~km}$ de Belo Horizonte, era composto de quatro prédios: o Cassino (hoje transformado em museu de belas artes), a Casa de Bailes (onde hoje funciona um centro de estudos sobre urbanismo, arquitetura e design), o Iate Clube e a Igreja de São Francisco de Assis, totalmente decorada por Portinari. Esse foi o primeiro grande projeto de Oscar Niemeyer. 
10. Portinari of Brazil, (cat. expo., New York, The Museum of Modern Art, 1940), Nova York, 1940; Brazil Builds: Architecture New and Old, 1652-1942, Philip L. Goodwin E., (cat. expo., New York, The Museum of Modern Art, 1943), Nova York, 1943.

11. A primeira parte do artigo foi publicada inicialmente em 1953, em uma revista alemã intitulada Staden-Jahrbuch, e, em seguida, na primeira edição do livro de Candido de Mello e Souza, Literatura e sociedade: estudos de teoria et história literária, editado em 1965 em São Paulo (COELHO, 2012, p. 90).

12. Cf. o site de seus arquivos : www.casaguilhermedealmeida.org.br (Acesso em: 15 setembro 2013).

13. Sobre a importância Clement Greenberg para a crítica brasileira, cf. FABRIS, 1994a e também uma entrevista com o crítico de arte Rodrigo Naves: www.forumpermanente.org/rede/numero/ rev-numero7/entrevRodrigoNav (Acesso em: 15 setembro 2013).

\section{AUTOR}

\section{ANA PAULA CAVALCANTI SIMIONI}

Doutora em sociologia pela Universidade de São Paulo, é docente e pesquisadora no Instituto de Estudos Brasileiros da Universidade de São Paulo, onde desenvolve investigações sobre arte e gênero no Brasil, práticas e produções modernistas brasileiras e arte e cultura na Primeira República brasileira (1889-1930). 